\title{
Why nuclear energy is essential to reduce anthropogenic greenhouse gas emission rates
}

\author{
Agustin Alonso ${ }^{*}$, Barry W. Brook ${ }^{2}$, Daniel A. Meneley ${ }^{3}$, Jozef Misak ${ }^{4}$, Tom Blees ${ }^{5}$, and Jan B. van Erp ${ }^{6}$ \\ ${ }^{1}$ University Politecnica de Madrid, Madrid, Spain \\ ${ }^{2}$ University of Tasmania, Hobart TAS 7005, Australia \\ ${ }^{3}$ CEI and AECL, Ontario, Canada \\ ${ }^{4}$ UJV-Rez, Prague, Czech Republic \\ ${ }^{5}$ Science Council for Global Initiatives, Chicago, Il, USA \\ ${ }^{6}$ Illinois Commission on Atomic Energy, Chicago, Il, USA
}

Received: 6 May 2015 / Accepted: 8 September 2015

Published online: 27 November 2015

\begin{abstract}
Reduction of anthropogenic greenhouse gas emissions is advocated by the Intergovernmental Panel on Climate Change. To achieve this target, countries have opted for renewable energy sources, primarily wind and solar. These renewables will be unable to supply the needed large quantities of energy to run industrial societies sustainably, economically and reliably because they are inherently intermittent, depending on flexible backup power or on energy storage for delivery of base-load quantities of electrical energy. The backup power is derived in most cases from combustion of natural gas. Intermittent energy sources, if used in this way, do not meet the requirements of sustainability, nor are they economically viable because they require redundant, underutilized investment in capacity both for generation and for transmission. Because methane is a potent greenhouse gas, the equivalent carbon dioxide value of methane may cause gas-fired stations to emit more greenhouse gas than coal-fired plants of the same power for currently reported leakage rates of the natural gas. Likewise, intermittent wind/solar photovoltaic systems backed up by gas-fired power plants also release substantial amounts of carbon-dioxide-equivalent greenhouse gas to make such a combination environmentally unacceptable. In the long term, nuclear fission technology is the only known energy source that is capable of delivering the needed large quantities of energy safely, economically, reliably and in a sustainable way, both environmentally and as regards the available resource-base.
\end{abstract}

\section{Introduction}

The need to reduce anthropogenic greenhouse gas (AGHG) emissions is of great urgency if catastrophic consequences caused by climate change are to be prevented. However, while the United Nations Framework Convention on Climate Change (UNFCCC), through its various meetings of the Conference of the Parties (COP), has emphasized the role of renewable energy sources, it barely mentions nuclear energy and the important contribution that it is already making in reducing AGHG emissions and could increasingly be making in the future. This is difficult to understand because nuclear fission is the only major energy source that could sustainably, reliably and economically provide the large quantities of clean energy that will be needed to make substantial progress in reducing AGHG emissions.

\footnotetext{
*e-mail: agustin.alonso@nexus5.com
}

When addressing issues related to the long-term energy policy, two important questions need to be asked, namely:

- Is it possible to replace all or most fossil-derived energy with renewables and, if so, would this be sustainable and economically viable?

- Is nuclear energy sustainable and what should its role in the energy mix be?

The term sustainable is generally understood, Brundtland Commission [1], to mean "meeting the needs of the present without compromising the ability of future generations to meet their own needs". In the context of energy options, 'sustainable' implies the ability to provide energy for indefinitely long time periods (i.e., on a very large civilization spanning time scale) without depriving future generations and in a way that is environmentally friendly, economically viable, safe and able to be delivered reliably. It should thus be concluded that, in this context, the term 'sustainable' is more restrictive than the term 'renewable', as large scale renewable 
systems backed by fossil fuels cannot be considered clean sources of electricity. On the other hand, nuclear energy from fission of uranium and plutonium is sustainable, meeting all of the above-mentioned criteria as discussed later.

The energy consumption in industrial nations may be roughly divided in three equal parts, namely:

- generation of electrical energy;

- heat in industrial processes and space heating;

- and transportation.

Nuclear fission is a low AGHG emission energy source that is already widely deployed for generation of electrical energy. Therefore, one effective way to reduce fossil fuel consumption and AGHG emissions would be by increasing the number of nuclear power plants for electrical energy generation.

It would be well within realistic limits to aim for replacement of the major part of the world's fossil fuelbased electrical energy generating capacity. Industrial nations should take the lead in this change because they are more capable of doing so, having already developed the necessary technological and mature economic base. In parallel to this major change in the generation of electrical energy, the use of fossil fuels for transportation should be reduced by greater reliance on nuclear-derived electrical energy as well as on liquid fuels produced synthetically by means of nuclear power plants. Also the use of nuclearderived process heat for industrial application and services should be encouraged [2]. Gradual conversion of the electrical generating capacity from fossil fuel-based to nuclear fission would be the way offering least economic disturbance.

\section{Intermittent 'renewables' when applied to the electric grid}

Wind and solar energy have served humanity well during centuries and in many applications, including grinding wheat, pumping water, sawing wood, drying foods and producing sea salt. Wind also served as an important energy source for transportation, making possible the exploration of the entire world by means of ships propelled by the wind. The common characteristic of these applications is that they are not time-constrained: if there is no wind today, the tasks can wait to be finished tomorrow or the ships will arrive somewhat later. This is not possible if intermittent renewable energy sources are used for base-load delivery of electrical energy to the grid, as strict demands have to be fulfilled instantaneously and completely.

\subsection{Grid-connected 'renewables' with gas-fired backup are not sustainable}

Intermittent 'renewables' are, in certain applications, not 'sustainable' because not all necessary criteria are being met. Intermittent 'renewable' energy sources, when used for large-scale delivery of energy to the electric grid, require the availability of energy storage facilities or flexible backup power plants capable of rapid output adjustments. This is

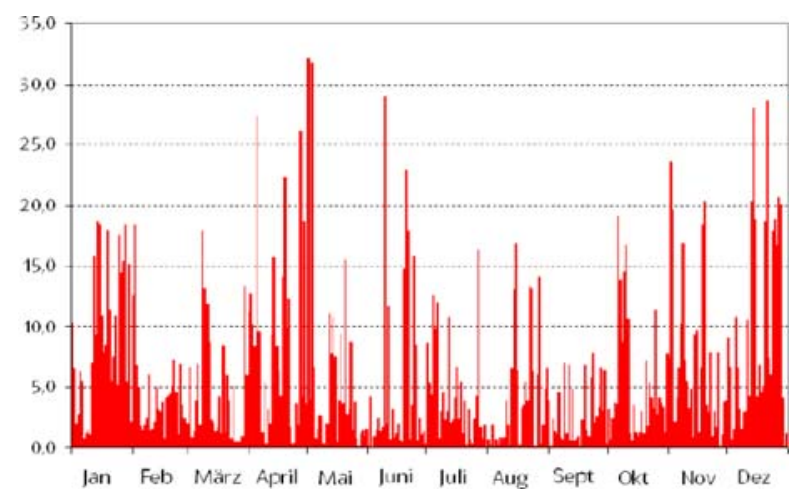

Fig. 1. Intermittence of wind energy in E.ON-grid in Germany (from Ref. [3]).

because wind turbines and solar/photovoltaic plants will vary their output between $0 \%$ and $100 \%$ of nameplate capacity, as it can be observed in the typical example given in Figure 1.

As energy from the grid is generated and consumed simultaneously, there can be no mismatch if grid stability and frequency are to be maintained within strict tolerances. The backup power is usually provided by gas-fired stations because technology for storing large amounts of electricity is not yet available. Although reversible pumped hydropower stations can be used to store potential energy, there are siting, technical and economic limitations that prohibit their widespread use. Gas-fired plants emit carbon dioxide and are associated with leakage of methane (the primary component of natural gas) into the atmosphere, which is a strong AGHG emitter. Only if the backup energy is delivered by hydro-electrical energy plants or similar means to store and control the generated energy, then gridconnected intermittent 'renewables' can be qualified as sustainable.

\subsection{Grid-connected 'renewables' are not economically viable}

Averaged over a year, wind/solar photovoltaic systems deliver from $25 \%$ to $45 \%$ of their nameplate production capacity. Therefore, the backup power plants or energy storage facilities will have to deliver the remaining $75 \%$ to $55 \%$ of the energy. Seasonal variability is another major, yet rarely acknowledged, impediment to all-renewables scenarios, as it is seen in Table 1.

Advocates often dismiss the issue of seasonal variability, pointing out that the wind blows more in the winter when solar output is minimal, and asserting that wind and solar balance out on a daily basis because wind blows more at night. However, these generalizations do not hold up to scrutiny. While some areas of the world do have more wind in the winter, others do not.

The backup power for wind/solar photovoltaic plants depends in most cases on combustion of less expensive natural gas. Storage may be of various types: potential energy storage capacity may be created by pumping up water 
Table 1. Seasonal variability of wind-generated electrical energy in Texas, USA. Highest and lowest monthly generation values $(\mathrm{GWh})$.

\begin{tabular}{llll}
\hline Year & $\begin{array}{l}\text { Highest value } \\
\text { (month) }\end{array}$ & $\begin{array}{l}\text { Lowest value } \\
\text { (month) }\end{array}$ & $\begin{array}{l}\text { Ratio } \\
\text { (high/low) }\end{array}$ \\
\hline 2009 & 1,993 (April) & 1,341 (July) & 1.44 \\
2010 & 2,721 (April) & 1,589 (Sept.) & 1.75 \\
2011 & 3,311 (June) & 1,694 (Sept.) & 1.95 \\
2012 & 3,131 (March) & 1,821 (Aug.) & 1.74 \\
2013 & 3,966 (May) & 2,023 (Sept.) & 1.96 \\
\hline
\end{tabular}

Source: Private communication, P. Peterson, Prof. Nuclear Engineering, Univ. of California at Berkeley, USA

or compressing air, small scale storage could be achieved in condensers and batteries. However, most energy storage facilities are not cost-effective for base-load application and often have undesirable environmental impacts. Also, storage is associated with energy losses. Consequently, gridconnected wind/solar photovoltaic installation will usually rely on gas-fired backup power plants.

Many wind and solar photovoltaic installations are far removed from the load centers, requiring additional longdistance transmission lines, sized for their peak output, which are then under-utilized by from $55 \%$ to $75 \%$. Furthermore, the backup power plant will have to operate in stand-by mode, ready to adapt to the varying output (from $0 \%$ to $100 \%$ ) of the intermittent energy source. This results in a penalty on the overall thermal efficiency of the backup plant, which can be as high as $20 \%$. Grid-connected wind and solar photovoltaic installations will thus be dependent on subsidies because redundant and underutilized investments are necessary (i.e., for the intermittent energy source, for the backup source and for the additionally required transmission capability). In view of the above-given reasons, it has to be concluded that the combination of an intermittent energy source and its backup power plant will not be able to achieve economic viability, as illustrated in Table 2. However, in isolated

Table 2. Average power plant operating expenses for USA electric utilities (mS/kWh).

\begin{tabular}{lrrrrr}
\hline & 2008 & 2009 & 2010 & 2011 & 2012 \\
\hline Nuclear & & & & & \\
Operation & 9.9 & 10.0 & 10.5 & 10.9 & 11.6 \\
Maintenance & 6.2 & 6.3 & 6.8 & 6.8 & 6.8 \\
Fuel & 5.3 & 5.4 & 6.7 & 7.0 & 7.1 \\
Total & 21.5 & 21.7 & 24 & 24.7 & 25.5 \\
Intermittent plus gas turbine & & & \\
Operation & 3.8 & 3.0 & 2.8 & 2.8 & 2.5 \\
Maintenance & 2.7 & 2.6 & 2.7 & 2.9 & 2.7 \\
Fuel & 64.2 & 52.0 & 43.2 & 38.8 & 30.5 \\
Total & 70.7 & 57.6 & 48.7 & 44.5 & 35.7 \\
\hline
\end{tabular}

Source: USA Energy Information Administration locations and some processes without access to a large electric grid, intermittent energy sources either directly or combined with storage capacity may be economically viable.

Much confusion exists concerning the generating cost per $\mathrm{kWh}$ for wind and solar plants. In this respect, it is of interest to distinguish clearly between the 'bare' cost of a $\mathrm{kWh}$ generated by wind or solar photovoltaic installations that is consumed or stored locally and the cost of a $\mathrm{kWh}$ delivered to the electrical grid. In the latter case, it is necessary to account for the investments in the backup power and transmission capacity. The difference between these two prices is very substantial; the cost per $\mathrm{kWh}$ delivered to the grid in most cases being several hundred percent higher than the 'bare' cost. As an example, Table 2 shows that for the combination of intermittent energy source with gas-fired backup power, the cost for fuel per $\mathrm{kWh}$ varies between 5 and 12 times the cost for operation and maintenance.

\subsection{Grid-connected 'renewables' have deleterious consequences}

Grid-connected intermittent energy sources will cause grid disturbances that will deleteriously affect the grid's reliability, particularly if the installed capacity of the intermittent sources becomes a high percentage of the grid's total capacity. Delivery unreliability of the electrical grid can have serious economic and social consequences as has been observed when long-lasting blackouts occurred in large urban areas. To date, in most grids, 'renewables' have only reached a relatively low market penetration and so have been able to rely mostly on existing marginal capacity, or on large import-export capacity of interconnected other grids.

Problems will emerge when the percentage of gridconnected intermittent energy sources exceeds the existing marginal capacity (without availability of adequate dedicated back-up power capacity) and it becomes necessary for the base-load plants to function as back-up plants. This mode of forced 'accommodative' operation penalizes nuclear power plants more than it does fossil-fired plants because the capital-cost component of the generating cost for the former is relatively high and the fuel cost component is low, whereas for the latter the reverse is true, as shown in Table 3.

This practice of distorting the energy market by subsidies and supporting regulations has serious and undesirable consequences, resulting in closure of base-load

Table 3. Generation cost breakdown (\%).

\begin{tabular}{lllr}
\hline Component & Nuclear & Coal & Gas \\
\hline Capital & 59 & 42 & 17 \\
Fuel & 15 & 41 & 76 \\
Operation \& Maintenance & 26 & 17 & 7 \\
\hline
\end{tabular}

Source: OECD/International Energy Agency 
generating capacity (including nuclear power plants), loss of grid reliability and higher net greenhouse gas emissions. This issue is of particular relevance for countries having an interconnected grid with an adjacent country that is relying (or is planning to rely) to a large extent on intermittent 'renewable' energy sources. In this respect, the question should be raised whether a country with a large installed wind/solar electrical generating capacity should be required to pay a connection fee to compensate adjacent countries for the use of their interconnected electric grids for providing backup power capacity.

It is often claimed by advocates of 'renewables' that the problems associated with the intermittency of wind and solar energy can be overcome by performing more research and carrying out more engineering development. Unfortunately, no level of research and development will be able to overcome the fact that the sun does not always shine and that the wind does not always blow. Not even the muchpraised 'smart grid' can change this inconvenient fact.

\subsection{The relevance of methane as a greenhouse gas}

Methane, $\mathrm{CH}_{4}$, the main component of natural gas, is a potent greenhouse gas as compared to carbon dioxide, $\mathrm{CO}_{2}$; making it one of the six gases considered in the Kyoto Protocol, the second in importance. To measure the relative climate importance of the two gases, the International Panel on Climate Change (IPCC) has introduced the concept of global warming potential (GWP) [4] which is defined (glossary) as:

"Global warming potential (GWP), index based on radiative properties of greenhouse gases measuring the radiative forcing following a pulse emission of a unit of gas of a given greenhouse gas in the present day atmosphere integrated over a chosen time horizon, relative to that of carbon dioxide. The GWP represents the combined effect of the different times these gases remain in the atmosphere and their relative effectiveness in causing radiative forcing."

The radiative forcing of a greenhouse gas is itself defined [4] (glossary) as:

"Radiative forcing, change in the net, downward minus upward, radiative flux (expressed in $\mathrm{W} . \mathrm{m}^{-2}$ ) at the tropopause or top of the atmosphere due to a change in an external driver of climate change, such as, for example in the change in the concentration of a gas or the output of the sun."

The GWP of any gas is calculated through the expression

$$
G W P_{m}(t)=\frac{\int_{t_{r}}^{t_{h}} a_{m} C_{m}(t) d t}{\int_{t_{r}}^{t_{h}} a_{c} C_{c}(t) d t},
$$

where sub-index $m$ represents methane and $c$ carbon dioxide; $a$ is the radiative forcing of the gas and $C(t)$ the time function, which represents the evolution of the gas in the atmosphere after the release of a pulse emission of a unit of gas. The integration goes from the time of release, $t_{\mathrm{r}}$, to

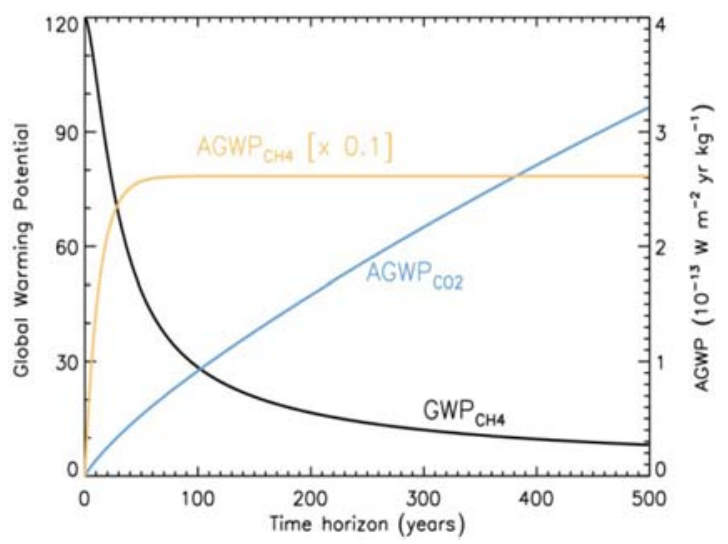

Fig. 2. Value of methane global warming potential, $\mathrm{GWP}_{\mathrm{CH}_{4}}$, as a function of time horizon (taken from Ref. [5]).

the selected time horizon, $t_{\mathrm{h}}$. Function $C(t)$ takes into account the rather complicated chemical reactions and other removal processes that take place among the different constituents in the atmosphere causing the disappearance of the released gases.

Each integral term in the definition is also called the absolute global warming potential (AGWP) of the concerned and the reference gas and is measured in $\mathrm{W} / \mathrm{m}^{2} / \mathrm{y} / \mathrm{kg}$. To estimate the magnitudes defined above, the IPCC has provided the graph reproduced in Figure 2.

It is accepted that a pulse release of methane in the atmosphere will be removed exponentially with time by getting involved in chemical reactions with hydroxyl radicals $(\mathrm{OH})$ present in the atmosphere. The coefficient in the exponential function is the inverse value of the so-called turn over or global atmospheric lifetime of methane, represented by symbol $T$. This symbol is given the value of $11.2+$ 1.3 years. The $\mathrm{AGWP}_{\mathrm{CH}_{4}}$ is then obtained by the equation:

$$
\mathrm{AGWP}_{\mathrm{CH}_{4}}=\int_{0}^{t} a_{m} e^{-\frac{t}{T}} d t=a_{m} T\left(1-e^{-\frac{t}{T}}\right)
$$

In less than a century, the $\mathrm{AGWP}_{\mathrm{CH}_{4}}$ reaches an asymptotic value, $a_{m} T$, which is the product of the radiative forcing of methane multiplied by the assumed lifetime of methane in the atmosphere measured in $\mathrm{W} / \mathrm{m}^{2} / \mathrm{y} / \mathrm{kg}$. Note that the graph in Figure 2 is reduced by a factor of 10 .

The behavior of carbon dioxide in the atmosphere includes a variety of phenomena, which could not be represented by a single lifetime; as seen in the blue curve, the $\mathrm{AGWP}_{\mathrm{CO} 2}$ is less than the one for methane because its radiative forcing is smaller; moreover, carbon dioxide in the atmosphere never reaches an asymptotic value because a small fraction of the carbon dioxide emitted is not removed from the atmosphere by natural processes, while the rest of the processes are described by exponential functions with long lifetime.

The ratio of the two curves is the $\mathrm{GWP}_{\mathrm{CH}_{4}}$, a decreasing function with increasing time horizon; when the time horizon approaches the time of release the $\mathrm{GWP}_{\mathrm{CH}_{4}}$ tends to 120 , which should be interpreted as the radiative forcing 
of the methane relative to the one of carbon dioxide. From the graph it is deduced that the $\mathrm{GWP}_{\mathrm{CH}_{4}}$ values are about 63, 21 and 3, obtained from calculations, for respective time horizons of 20,100, and 500 years. The IPCC recommends using a time horizon of 100 years.

The methane contents in the atmosphere started to grow since 1750, the year considered as the start of the industrial revolution; at that time, the methane content in the atmosphere was $0.722 \mathrm{ppm}$; it grew exponentially until about 1980, in the 1990s the rise slowed down and reached the value of $1.893 \mathrm{ppm}$ in 2011, an increment of some $1.171 \mathrm{ppm}$, i.e. an average increase of $138 \%$. This value is compared with the same temporal increment of carbon dioxide in the atmosphere from $280 \mathrm{ppm}$ in 1750 to the current $395 \mathrm{ppm}$, an increment of $115 \mathrm{ppm}$, i.e. an average increase of $36 \%$. From these values, it is deduced that from the year 1750 to now, i.e. 260 years, for which the $\mathrm{GWP}_{\mathrm{CH}_{4}}$ is around 10 , the increase in the climatic relevance of methane has been 40 times larger than that for carbon dioxide. This proves the relevance of methane as a greenhouse gas.

As in 1750 , the atmospheric content of methane was probably in equilibrium and mainly caused by natural sources, it is considered that the noted increment is mainly due to anthropogenic reasons. The cause of the increase has to be attributed to direct atmospheric releases of natural gas during its geological extraction, purification, flaring and venting, liquefaction and transport, as well as storage, manipulation and use of the gas in electricity-generating station and from poor gas combustion. There is much literature, even regulations, on the mass fraction of natural gas leakages from all these operations. Values are quoted [6] from $2 \%$ to $10 \%$ of natural gas releases when the complete fuel cycle is considered: from the source to the power plant.

When natural gas is used instead of coal or to back up the intermittency and variability of wind/solar photovoltaic systems for load-based electricity generation, the expected climatic effect from the natural gas directly released to atmosphere, also called the fugitive methane, has to be added to the corresponding release of carbon dioxide from the natural gas combustion process. To determine the relevance of the radiative forcing of the leaked natural gas, the IPCC [4] has introduced the concept of equivalent carbon dioxide emission (glossary):

"Equivalent carbon dioxide emission, the amount of carbon dioxide emission that would cause the same integrated radiative forcing over a given time horizon as an emitted amount of a greenhouse gas or the mixture of greenhouse gases. The equivalent carbon dioxide emission is obtained by multiplying the emission of the greenhouse gas by its global warming potential for the given time horizon".

The use of the equivalent carbon dioxide concept when applied to methane permits to compare the GWP of a given coal station with the one for a gas-fired installation of the same power when gas leakages are included. That relation is obtained from the following algorithm:

$$
R_{m / c}=m\left\{1+\psi \frac{M_{\mathrm{CH}_{4}}}{M_{\mathrm{CO}_{2}}}\left(\mathrm{GWP}\left(t_{\mathrm{h}}\right)\right)\right\},
$$

Table 4. Ratio between the greenhouse gases from a gasfired station including methane leakages and from a coalfired plant of equal power.

\begin{tabular}{llll}
\hline$\psi$ & \multicolumn{3}{c}{$\mathrm{GWP} / \mathrm{t}_{\mathrm{h}}$} \\
\cline { 2 - 4 } & $120 /$ as. & $63 / 20$ & $21 / 100$ \\
\hline 0.02 & 0.93 & 0.73 & 0.57 \\
0.04 & $\mathbf{1 . 3 7}$ & 0.95 & 0.65 \\
0.06 & $\mathbf{1 . 8 0}$ & $\mathbf{1 . 1 8}$ & 0.90 \\
\hline
\end{tabular}

where $m$ is the ratio between the masses of carbon dioxide generated in the combustion of methane and coal per unit of energy generated in the respective electrical power plants, it depends on the quality of the fossil fuels and the efficiency of the plant, the average value of $\frac{1}{2}$ is frequently used in calculations; $\psi$ is the fraction of fugitive methane directly discharged to the atmosphere from leakages in the natural gas cycle; $M_{\mathrm{CH}_{4}} / M_{\mathrm{CO}_{2}}$ is the ratio between the molecular mass of methane and carbon dioxide needed to estimate the methane carbon dioxide equivalent, and $\operatorname{GWP}\left(t_{\mathrm{h}}\right)$ the global warming potential of methane for time horizon $\left(t_{\mathrm{h}}\right)$. In Table 4, estimations are presented for different leakage fractions, the asymptotic and horizon times of 20 and 100 years, corresponding to the GWP $\left(t_{\mathrm{h}}\right)$ of 120,63 and 21 .

It is observed from the table that for gas leakages of $2 \%$, the breakeven, although close, is not reached even for the asymptotic value, while for leakages of $4 \%$, the breakeven is close for a time horizon of 20 years. Leakages superior to $6 \%$ could not be accepted even for time horizons of 100 years. The results clearly indicate that replacing coal-fired with gas-fired plants does not provide any relevant climate reduction unless gas leakage is reduced to less than $2 \%$.

Likewise, the climatic effect of a gas-fired backup power is obtained by adding the carbon dioxide equivalent of the fugitive methane to the carbon dioxide generated during the fraction of the time that the backup power is needed. In this case, the ratio between the methane/carbon dioxide equivalent due to the fugitive methane and the carbon dioxide release from the combustion of the gas in the backup plant is given by the equation:

$$
R_{m / c}=\left\{\psi \frac{M_{\mathrm{CH}_{4}}}{M_{\mathrm{CO}_{2}}}\left(G W P\left(t_{h}\right)\right)\right\} .
$$

In Figure 3, estimations are presented for different leakage fractions, the asymptotic and horizon times of 20 and 100 years, corresponding to the $\operatorname{GWP}\left(t_{h}\right)$ of 120,63 and 21.

As in Table 4, it is also observed that for gas leakages of $2 \%$, the breakeven, although close, is not reached even for the asymptotic value of the GWP, while for $4 \%$ leakage breakeven is close for the 20-year GWP. It is then concluded that for leakages above $2 \%$ and certainly superior to $4 \%$ it will be climatically advantageous to backup wind/solar photovoltaic systems with coal-fired instead of gas-fired plants. 


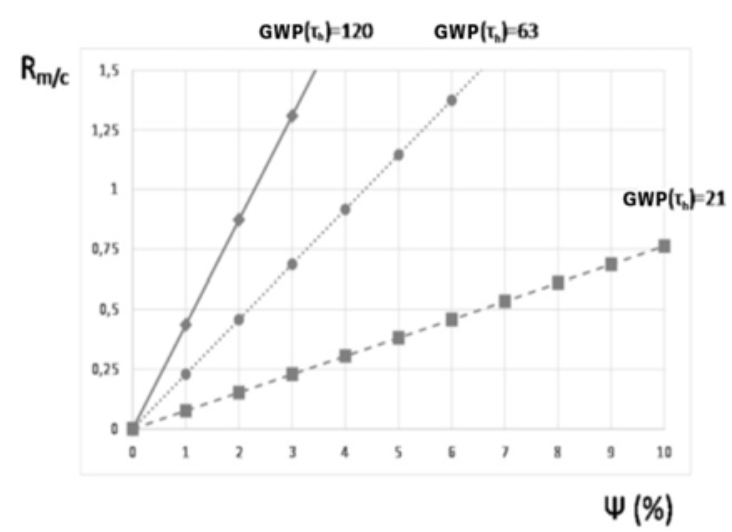

Fig. 3. Ratio between the carbon dioxide equivalent for fugitive methane and the carbon dioxide emitted in a wind/solar photovoltaic system backed by a gas-fired plant.

\section{The essential role of nuclear energy in reducing greenhouse gas emissions}

Nuclear fission energy is capable of replacing most of the stationary tasks now performed by the combustion of fossil fuels. Other than the generation of electrical energy, it may equally well be used for production of process heat and hydrogen as well as for desalination. However, many environmental organizations and governments oppose the application of nuclear energy. Among the reasons usually given are:

- nuclear energy is not sustainable;

- nuclear energy is not economically viable;

- and nuclear energy is not safe.

\subsection{Nuclear energy from fission is sustainable}

Today's commercially available uranium-fueled nuclear power plants can provide the world with clean, economical and reliable energy well into the next century on the basis of the already-identified uranium deposits. Furthermore, nuclear reactors operating with fast neutrons are able to fission not only the rare uranium isotope U-235 but also the $\mathrm{Pu}-239$ isotope generated from the transmutation of the abundant uranium isotope U-238. Thus, the deployment of fast-neutron fission reactors transforms uranium into a truly inexhaustible energy source, because of their ability to harvest up to one hundred times more energy from the same amount of mined uranium as the commercially available thermal reactors can achieve $[7,8]$.

This fast-neutron fission technology has already been proven, all that is further needed is to develop it to a commercial level and deploy it widely [9]. The amount of depleted uranium that is available and stored at enrichment plants in a number of countries, together with the uranium recoverable from used fuel elements, contains enough energy to power the world for several hundred years without additional mining. Afterwards, mining of small quantities of uranium in future centuries, including extracting uranium from lower-grade ores and, if necessary, from seawater, could satisfy global energy needs economically for as long as human civilization will endure.

\subsection{Nuclear energy from fission is economically viable}

Conditions for economic viability of nuclear energy are:

- presence of a level playing field, i.e., an open market that is not skewed in favor of some technologies by means of subsidies and/or by a legally imposed priority access for delivery to the electrical grid at a fixed high price;

- standardization of the plants, built in series and supported by a standardized supply chain;

- a long-term governmental energy policy (stable over a time period of several decades) including, among other features, good (unbiased, accurate, evidence-based) public information;

- a stable and streamlined licensing process that is technology-neutral, risk-informed and capable of resolving promptly any safety issues that may arise during construction and operation;

- and gradual introduction of the concept of payment for external costs, applied to all energy technologies and based on common standards.

The fact that nuclear energy is economically viable has been shown, among others, by the national energy program in France where the unit price of electricity in a market supplied about $75 \%$ by nuclear fission is among the lowest worldwide. An important additional benefit of this reliance on nuclear energy is that per capita emission of greenhouse gases in France is among the lowest for industrial nations worldwide and many times lower than in otherwise similar countries that have no nuclear power plants and that rely on a mix of fossil fuels and renewables.

An important aspect of long-term commercial viability of power plants is the future development of their respective fuel costs. Nuclear power plants rank best in this respect because their sensitivity to fuel-cost increases is small as seen in Table 5.

The current temporary abundance (in the USA) of lowcost natural gas may seem to make gas-fired stations appear to be economically attractive. However, this will change because it can be expected that gas prices will rise substantially during the $60+$ lifetime of new-build nuclear power plants.

Thus, the fuel supply side of nuclear power reactors eliminates any doubt concerning its sustainability. As to the materials used in the construction of nuclear power

Table 5. Percent sensitivity of generating cost to a $50 \%$ increase in fuel price.

\begin{tabular}{llll}
\hline Nuclear & IGCC & Coal Steam & CCGT \\
\hline 3 & 20 & 22 & 38 \\
\hline
\end{tabular}

IGCC: integrated gasification combined cycle; CCGT: combine cycle gas turbine. Source: WEO '06/OECD/IEA World Energy Outlook 2006 
plants, it is noted that none of them is in short supply (and most are readily recyclable), so that they too do not constitute a sustainability impediment.

\subsection{Nuclear energy from fission has a low environmental impact}

Numerous scientific comparisons have shown that nuclear fission is among the energy sources that are least polluting and have the lowest overall environmental impact [10]. Operating nuclear power plants do not produce air pollution nor do they emit $\mathrm{CO}_{2}$. Any $\mathrm{CO}_{2}$ that is associated with nuclear finds its origin in the mining of uranium and in the production of structural materials necessary for the building of the nuclear plants; small amount of $\mathrm{CO}_{2}$ are released during the periodic testing of emergency diesel generators and on the use of external power during refuelling outages and maintenance.

Annually, the 435 operating nuclear power plants prevent the emission of more than 2 billion tons of $\mathrm{CO}_{2}$. By contrast, coal-fired stations emit worldwide about 30 billion tons of $\mathrm{CO}_{2}$ per year and cause health effects and premature death through air pollution and dispersion of pollutants, including mercury and other poisonous materials [11]. It is to be noted that nuclear power plants emit less radioactive material than do coal-fired stations (uranium and other radioactive isotopes are found naturally in coal ash and soot) [12]. The most severe environmental impact associated with nuclear energy is due to the mining of uranium. However, the need for uranium mining will be reduced after fast reactors have become commercially available, as may be expected within the coming decades.

New methods for efficiently recycling the used fuel will reduce the radioactive hazards as well as the volume of the waste that must be kept isolated from the environment. New technologies have been actively developed to reduce the level of radioactivity of a repository containing this type of waste so that the activity of the waste, after a few centuries, will be comparable to that of the natural uranium deposits that are widely distributed around the world. Furthermore, modern waste isolation technology will equal or exceed the level of isolation originally provided by nature for radioactive ores. In this way the waste will be reduced to a historical time scale of a few hundred years, rather than a geological time scale of hundreds of thousands of years. Furthermore, it is important to note that this waste will be disposed of in an environmentally inert form, i.e., ceramic or vitrified solids that will not start leaching any material into the environment for thousands of years, long after their radioactivity will have dissipated. On the other hand, large amounts of solid and gaseous waste from coal-fired stations (including mercury and heavy metals) will remain poisonous in perpetuity and they are neither kept well-guarded nor well separated from the environment.

\subsection{Nuclear energy from fission meets high safety standards}

Nuclear fission is among the safest energy technologies in terms of health effects and fatalities as seen in Figure 4. This

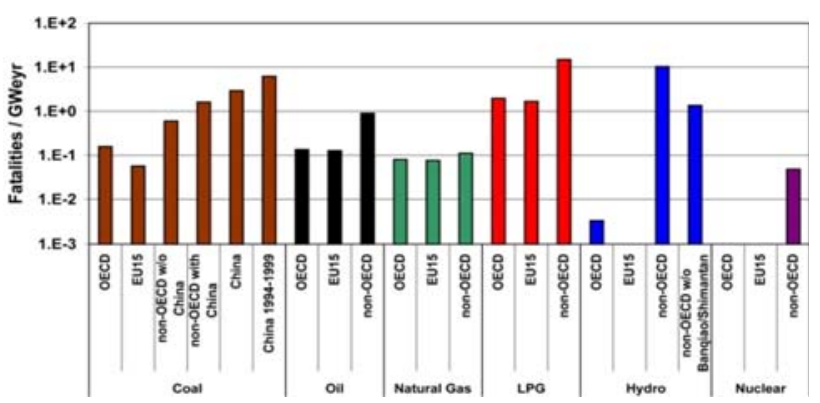

Fig. 4. Comparison of energy-related damage (fatalities per $\mathrm{GW} / \mathrm{y})$. Based on historical experience of severe accidents in OECD, non-OECD countries and EU-15 (from Ref. [13]).

is true notwithstanding the three major nuclear accidents that have occurred, namely the 1979 Three Mile Island (TMI) in the USA, the 1986 Chernobyl in Ukraine, and the 2011 Fukushima in Japan. Of these three, only the Chernobyl accident caused a number of fatalities, namely among those persons that were directly exposed to high radiation levels during the urgent initial part of the cleanup operation.

The total number of nuclear-caused fatalities is relatively small (less than one hundred) compared to the number of annual fatalities in the coal and oil/gas industry as seen in Table 6 where there are included the global average values of the mortality rate per billion $\mathrm{kWh}$ due to all causes as reported by the World Health Organization (WHO).

Both the accident at Chernobyl and that at Fukushima caused considerable land contamination and required evacuation of the population. However, in both cases the major part of the evacuated areas has/had radiation levels that are lower than the normal background level in many regions around the world, raising the question of how much evacuation was really necessary and for how long. In the case of TMI-2, there was no land contamination, but a short-term evacuation was imposed as a cautionary

Table 6. Mortality rates (deaths per TWh) from energy sources.

\begin{tabular}{lcl}
\hline Coal global average & 100 & $50 \%$ global electricity \\
Coal China & 160 & $75 \%$ China's electricity \\
Coal USA & 15 & $44 \%$ USA electricity \\
Oil & 36 & $36 \%$ global $/ 8 \%$ electricity \\
Natural gas & 4 & $20 \%$ of global electricity \\
Biofuel/biomass & 24 & $21 \%$ global energy \\
Solar (rooftop) & 0.44 & $<1 \%$ global electricity \\
Wind & 0.15 & $\sim 1 \%$ global electricity \\
$\begin{array}{l}\text { Hydro-global } \\
\text { average }\end{array}$ & 1.4 & $15 \%$ global electricity \\
$\begin{array}{l}\text { Nuclear global } \\
\text { average }\end{array}$ & 0.04 & $17 \%$ global electricity \\
\hline
\end{tabular}

Source: Updated data from: World Health Organization 
measure. It should be noted that land contamination is not limited to severe nuclear accidents; it has also occurred following severe accidents in the chemical industry, in which the contaminants were extremely deadly and long lasting (e.g. Bhopal, India; Seveso, Italy).

The radioactive isotopes of iodine (I-131, half-life 8 days) and cesium (Cs-137, half-life 30 years) have dominating importance in accidents in which the containment is breached and radioactivity is released into the environment. The short half-life of I-131 and its biological accumulation in the thyroid requires simple precautions, such as ingesting a small dose of potassium iodine, to prevent its health effects. However, Cs-137 will stay in the environment for a longer time period that is determined by its effective soil removal half-life, i.e., the combination of its radioactive half-life and the rate of removal from the soil surface by natural processes and by adding manure and fertilizers as it has been done in regions contaminated by the Chernobyl releases. This latter process can be accelerated by removal of a thin layer of the top soil in areas where the radiation level exceeds the allowable radiation level, as it is being practiced in soils contaminated by the Fukushima Daiichi accident.

Natural background radiation varies greatly over the world (depending on soil composition and the location's elevation) but higher background has not been found to be correlated with higher rates of cancer in the population. The average background radiation at sea level in much of the world is about three milli-Sievert $(\mathrm{mSv})$ per year whereas that in many regions around the world is considerably higher. As an example, at Ramsar in Iran, the background radiation level is about $138 \mathrm{mSv}$ per year, i.e. about 46 times higher than the average background. Nevertheless, the incidence of cancer in the local population of regions with high background radiation has not been observed to be higher than the normal rate.

The economic damage associated with nuclear accidents can be substantial, as was demonstrated in the abovementioned three major accidents. This potential for severe economic damage is a strong incentive on the part of the owner/operator of the nuclear power plant to observe extreme caution, observing strictly all safety-related rules and regulations and maintaining a strict safety culture (even without continuous monitoring by the relevant regulatory organization).

As is normal in the evolution of any technology, also the new designs of nuclear power plants incorporated many new safety-related improvements, mainly coming from the worldwide system of analysing, reporting and incorporating operating experience conducted by the World Association of Nuclear Operators (WANO) created after the Chernobyl accident. WANO also conducts periodic external peer reviews of the operational safety of each one of the operating power plants in the system.

The International Atomic Energy Agency (IAEA) produces safety principles, safety requirements and safety guides created by international consensus, to help countries to create their own regulatory regimes, maintains and distributes an Incident Reporting System (IRS) to share operating incidents and an International Nuclear Event Scale, (INES), where events, incidents and accidents are classified. Under the request of governments, the Agency also performs independent evaluations of the operational and safety culture of the requested plant and on the regulatory completeness and practices of the regulatory organization. The Agency is also depositary of the many existing international conventions, of which the Nuclear Safety Convention is among the most relevant.

These international activities, together with the national research and advances in technology and regulation, have created a high level of safety assurance for future nuclear power plants and substantial safety improvements in currently operating nuclear stations.

Public opposition to nuclear energy is in part due to fear of radiation caused by recollection of the effects of nuclear weapons used during World War II and by sensationalized media coverage of nuclear incidents. Another cause of the public fear of radiation is the use of the scientifically unsubstantiated linear-no-threshold (LNT) hypothesis in which it is erroneously assumed that the biological effects of nuclear radiation are linear even at very low radiation doses [14].

\section{Conclusions}

Nuclear power plants are capable of sustainably and reliably supplying the large quantities of clean and economical energy needed to run industrial societies with minimal emission of greenhouse gases.

The world's industrial nations should take the lead in transforming the major part of their electrical energy generating capacity from fossil fuel-based to nuclear fissionbased.

Wind/solar photovoltaic systems with gas-fired backup power stations will not be able to reduce the rate of greenhouse-gas emission, even for relatively low atmospheric gas leakage rates.

Distorting the electricity market with subsidies and by legislation to attract intermittent energy technologies into applications for which they are not well suited, is costly, economically wasteful and counterproductive.

Countries that depend on imported natural gas should be aware that they carry full responsibility for their part of the global consequences of the associated atmospheric leakage of methane, including the leakage taking place outside their borders.

Only in specific cases and for some isolated locations without access to an electric grid, may the use of intermittent energy sources for electrical energy generation be economically viable.

\section{References}

1. United Nations, Towards sustainable development, in Report of the World Commission on Environment and Development: Our Common Future (United Nations, New York, 1987), Part I, Chap. 2

2. D.A. Meneley, Nuclear Energy: The Path Forward, in CANADA: becoming a sustainable energy powerhouse, 1st Ed. (Canadian Academy of Engineering, Ottawa, Canada, 2014), Chap. 9 
3. The European Nuclear Energy Forum, SWOT Analysis of Energy Technologies, in 2nd Meeting, Prague, 22-23 May 2008 (2008), p. 20

4. IPCC, Climate Change 2013: The Physical Science Basis (World Meteorological Organization (WMO), United Nations Environmental Programme (UNEP), Genève, Switzerland, 2013)

5. IPCC 2013, The Physical Science Basis. Contributions of Working Group I of the Fifth Assessment Report of the Intergovernmental Panel of Climate Change (Cambridge University Press, Cambridge, New York, USA, 2013), Chap. 8, p. 712 , Fig. 8.9

6. NAS, in Proceedings of the National Academy of Science of the United States of America: Greater Focus Needed in Methane Leakage from Natural Gas Infrastructure, Washington DC, 2014, (2014), Vol. 109, No. 5

7. B.L. Cohen, Breeder Reactors: A Renewable Energy Source, Am. J. Phys. 51, 75 (1983)

8. D. Lightfoot et al., Nuclear Fission Fuel is Inexhaustible, in Climate Change Technology Conference, May 10-12, Ottawa, Canada, 2006 (2006)
9. C.E. Till, Y.I. Chang, Plentiful Energy: The Story of the Integral Fast Reactor (CreateSpace 2011)

10. P.A. Kharecha, J.E. Hansen, Prevented Mortality and Greenhouse Gas Emissions from Historical and Projected Nuclear Power, Environ. Sci. Technol. 47, 4889 (2013)

11. A. Gabbard, Nuclear Resource or Danger, ORNL 26, 1 (1993)

12. J.M. Cuttler, Remedy for Radiation Fear: Discharge the Politized Science, Dose Response J. 12, 170 (2014)

13. S. Hirschberg, C. Bauer, P. Burgherr, E. Cazzoli, T. Heck, M. Spada, K. Tryer, Health Effects of Technologies for Power Generation: Contributions from Normal Operation, Severe Accidents and Terrorist Threat, in Proceedings of PSAM 12 Conference, International Association for Probability Safety Assessment and Management, IAPSAM, Cal. 2014 (2014)

14. E.J. Calabrese, Road to Linearity: Why Linearity at Low Doses Became the Basis for Carcinogenic Risk Assessment, Arch. Toxicol. 83, 203 (2009)

Cite this article as: Agustin Alonso, Barry W. Brook, Daniel A. Meneley, Jozef Misak, Tom Blees, Jan B. van Erp, Why nuclear energy is essential to reduce anthropogenic greenhouse gas emission rates, EPJ Nuclear Sci. Technol. 1, 3 (2015) 